\title{
Berberine sensitizes nasopharyngeal carcinoma cells to radiation through inhibition of Sp1 and EMT
}

\author{
JUN WANG $^{1,2^{*}}$, MIN KANG $^{1 *}$, QIN WEN $^{1}$, YU-TAO QIN $^{1}$, ZHU-XIN WEI $^{1}$, \\ JING-JIAN XIAO ${ }^{1}$ and REN-SHENG WANG ${ }^{1}$ \\ ${ }^{1}$ Department of Radiotherapy, The First Affiliated Hospital of Guangxi Medical University, Nanning, Guangxi 530021; \\ ${ }^{2}$ Department of Oncology, The Central Hospital of Taian, Taian, Shandong 271000, P.R. China
}

Received April 22, 2016; Accepted June 7, 2016

DOI: $10.3892 / o r .2017 .5499$

\begin{abstract}
Nasopharyngeal carcinoma (NPC) is a tumor of epithelial origin with radiotherapy as its standard treatment. However, radioresistance remains a critical issue in the treatment of NPC. This study aimed to investigate the effect of berberine on the proliferation, cell cycle regulation, apoptosis, radioresistance of NPC cells and whether specificity protein $1(\mathrm{Sp} 1)$ is a functional target of berberine. Our results showed that treatment with berberine reduced the proliferation and viability of CNE-2 cells in a dose- and time-dependent manner. Berberine induced cell cycle arrest in the G0/G1 phase and apoptosis. In CNE-2 cells exposed to gamma-ray irradiation, berberine reduced cell viability at various concentrations $(25,50,75$ and $100 \mu \mathrm{mol} / \mathrm{l})$. Berberine significantly decreased mRNA and protein expression of Sp1 in the CNE-2 cells. Mithramycin A, a selective Sp1 inhibitor, enhanced the radiosensitivity and the rate of apoptosis in the CNE-2 cells. Berberine inhibited transforming growth factor- $\beta$ (TGF- $\beta$ )-induced tumor invasion and suppressed epithelialto-mesenchymal transition (EMT) process, as evidenced by increased E-cadherin and decreased vimentin proteins. Sp1 may be required for the TGF- $\beta 1$-induced invasion and EMT by berberine. In conclusion, berberine demonstrated the ability to suppress proliferation, induce cell cycle arrest and apoptosis, and enhance radiosensitivity of the CNE-2 NPC cells. Sp1 may be a target of berberine which is decreased during the radiosensitization of berberine.
\end{abstract}

\section{Introduction}

Nasopharyngeal carcinoma (NPC) is a common tumor which originates from epithelial cells located in the nasopharynx (1).

Correspondence to: Dr Ren-Sheng Wang, Department of Radiotherapy, The First Affiliated Hospital of Guangxi Medical University, 6 Shuangyong Road, Nanning, Guangxi 530021, P.R. China

E-mail: wangrsgx@163.com

"Contributed equally

Key words: berberine, nasopharyngeal carcinoma, radioresistance, specificity protein 1 , epithelial-to-mesenchymal transition
NPC has a complex etiology and specific world distribution, with most cases occuring in Southern China and Southeast Asia (2). Currently, radiotherapy is the standard therapeutic strategy for NPC (3). NPC in its early stage is highly radiosensitive. However, NPC usually shows radioresistance in the more advanced stage due to local recurrence and distant metastasis (4). Therefore, investigation of the molecular mechanisms that enhance radiosensitivity of NPC may be conducive to exploring novel therapeutic strategies thereby consequently improving clinical outcomes.

Transforming growth factor- $\beta$ (TGF- $\beta$ ) is a pluripotent cytokine that demonstrates distinct roles during tumorigenesis. In normal epithelial cells and early-stage cancer, TGF- $\beta$ is a strong inhibitor of cell growth. However, in late-stage cancer, TGF- $\beta$ increases tumor invasiveness and metastasis, thus contributing to tumor progression $(5,6)$. Recently, a growing number of studies suggest that TGF- $\beta$ signaling enhances the invasive and metastatic potential of various cancers by inducing a cellular process called epithelial-to-mesenchymal transition (EMT) (7). EMT is a reversible biologic program changing polarized epithelial cells into motile fibroblastoid cells. EMT is associated with increased invasion, migration, and cell proliferation of epithelial cancers, including NPC (8).

Berberine (2,3-methylenedioxy-9, 10-dimenthoxyprotoberberine chloride, BBR) (Fig. 1A) is a natural isoquinoline alkaloid derived from Berberis species. Berberine exhibits a variety of pharmacological effects with antibacterial, antifungal and anti-inflammatory activities (9). Recently, studies have shown that berberine exhibits anticancer activity in various cancers including NPC. Berberine can inhibit tumor metastasis, tumorigenicity and growth, and enhance radiosensitivity of NPC via regulation of multiple pathways (10-12). However, the molecular mechanisms underlying the radiosensitizing effects of berberine in NPC remain largely unclear.

Our laboratory previously found that specificity protein 1 (Sp1), a transcription factor, is overexpressed in NPC tissues compared with their adjacent normal tissues. High expression of Sp1 was found to be correlated with tumor invasion, distant metastasis and radioresistance in NPC patients (13). This indicates that Sp1 protein may mediate the signaling pathway of NPC radioresistance. However, currently there is no study concerning the regulation of $\mathrm{Sp} 1$ in the radiosensitizing effects of NPC. 
In this study, we investigated the effects of berberine on the proliferation, cell cycle and apoptosis of CNE-2 NPC cells, especially the effect on TGF- $\beta$-induced EMT which promotes NPC cell invasion, migration and metastasis. Our study also explored the roles of Sp1 in inhibition of TGF- $\beta$-induced EMT by berberine in NPC cells.

\section{Materials and methods}

Cell culture. The undifferentiated human NPC cell line CNE-2 was routinely maintained in RPMI-1640 medium (Invitrogen-Gibco, Carlsbad, CA, USA) supplemented with $10 \%$ fetal bovine serum (FBS) (Sijichun Bioengineering Materials Inc., Hangzhou, Zhejiang, China), 2 mM sodium pyruvate, $2 \mathrm{mM}$ L-glutamine (Invitrogen-Gibco), $100 \mathrm{U} / \mathrm{ml}$ penicillin and $100 \mathrm{U} / \mathrm{ml}$ streptomycin. Cells were cultured in a humid atmosphere of $5 \% \mathrm{CO}_{2}$ at $37^{\circ} \mathrm{C}$. CNE-2 cells were digested by trypsinization after reaching confluence and were subcultured in new culture dishes at lower densities.

Irradiation condition. The NPC cells at the logarithmic growth phase were randomly divided into 96 -well culture plates and incubated with berberine $(\mathrm{BBR})(0,25,50,75$ and $100 \mu \mathrm{mol} / \mathrm{l})$ or mithramycin A (Mith) $(100 \mathrm{nmol} / \mathrm{l})$ for $24 \mathrm{~h}$. Then the cells were exposed to (60)Co gamma rays with various doses of irradiation $(0,4,6$ and $8 \mathrm{~Gy})$ using a linear accelerator (Elekta, Stockholm, Sweden). The source-skin distance (SSD) technique was $80 \mathrm{~cm}$ and the depth was set at $0.8 \mathrm{~cm}$ to the bottom of the culture plates. The irradiation was performed for $72 \mathrm{~h}$ followed by MTT assay.

Cell proliferation assay. CNE-2 cells in the logarithmic growth phase were trypsinized and seeded in a 96-well plate at a density of $1 \times 10^{4}$ cells/well. After $24 \mathrm{~h}$, old medium was removed and incubated with fresh RPMI-1640 medium supplemented with $10 \%$ FBS and containing various concentrations of berberine $(0,25,50,75$ and $100 \mu \mathrm{mol} / \mathrm{l})$ for $6,12,24,48$ or $72 \mathrm{~h}$. Cell viability was measured using the MTT (Sigma Chemical Co., St. Louis, MO, USA) assay following the manufacturer's instructions. To assess cell viability, $10 \mu \mathrm{l}$ of MTT solution $(5 \mathrm{mg} / \mathrm{ml})$ was added into each well to incubate at $37^{\circ} \mathrm{C}$ for $4 \mathrm{~h}$. Centrifugation at $1,000 \mathrm{x} \mathrm{g}$ was performed for $10 \mathrm{~min}$ to remove the supernatant, and the obtained formazan pellet was dissolved with $100 \mu \mathrm{l}$ DMSO in each well. The absorbance at $570 \mathrm{~nm}$ wavelength was determined using a ELISA plate reader (Ricso RK201; Shenzhen Ricso Technology Co., Ltd., Shenzhen, China) to evaluate the amount of pellet. The surviving cells from each group were normalized to those of the controls and were expressed as percentage of cell viability. All experiments were repeated at least three times.

Cell cycle analysis. CNE-2 cells at the logarithmic growth phase were randomly seeded in 60-mm culture dishes, and were incubated with serum-free medium after reaching $50 \%$ confluence to induce cell quiescence. After $24 \mathrm{~h}$, cells were incubated with different concentrations of berberine $(0,25,50$, 75 and $100 \mu \mathrm{mol} / \mathrm{l}$ ) for 24,48 or $72 \mathrm{~h}$ in complete medium. Cells were harvested by trypsinization and centrifugation at $1,000 \mathrm{x} \mathrm{g}$ for $5 \mathrm{~min}$, and then cells were mixed with cold $70 \%$ ethanol for resuspension. Then the suspension was incubated with
$1 \mathrm{ml}$ propidium iodide (PI) solution $(20 \mu \mathrm{g} / \mathrm{ml} \mathrm{PI} ; 100 \mu \mathrm{g} / \mathrm{ml}$ RNase A) for $30 \mathrm{~min}$, and were analyzed on a flow cytometry (FACScan; Becton-Dickinson, San Francisco, CA, USA). Data were acquired from 10,000 cells and analyzed by Lysis II software (Becton-Dickinson). The cell number in the G0/G1, S and $\mathrm{G} 2 / \mathrm{M}$ phases were calculated and the respective percentages were calculated.

Cell apoptosis assay. CNE-2 cells were randomly seeded in 60-mm culture dishes and incubated with various concentrations of berberine $(0,25,50,75$ and $100 \mu \mathrm{mol} / \mathrm{l})$ for $24 \mathrm{~h}$. Then cells were harvested by trypsinization from each group and underwent centrifugation at $1,000 \mathrm{x} \mathrm{g}$ for $5 \mathrm{~min}$. The cell were incubated with $100 \mu \mathrm{l} 1 \mathrm{X}$ binding buffer containing $5 \mu \mathrm{l}$ Annexin V and $5 \mu \mathrm{l}$ PI (final concentration of $10 \mu \mathrm{g} / \mathrm{ml}$ ). After a 15-min incubation in the dark, apoptosis of samples was determined by flow cytometry (FACScan; BectonDickinson), and data were analyzed using CellQuest software (Becton-Dickinson, Franklin Lakes, NJ, USA). At least 10,000 events were analyzed for each sample.

Quantitative real-time polymerase chain reaction ( $q R T-P C R$ ). CNE-2 cells were incubated with various concentrations of berberine $(0,100$ and $300 \mu \mathrm{mol} / \mathrm{l})$ for 12,24 or $48 \mathrm{~h}$, and total RNA was extracted using TRIzol ${ }^{\circledR}$ reagent (Life Technologies, Carlsbad, CA, USA) according to the manufacturer's instructions. After treatment with DNase, complementary DNA (cDNA) was synthesized from total RNA $(2 \mu \mathrm{g})$ by reverse transcription using the SuperScript III enzyme (both from Life Technologies). The mRNA level of Sp1 was determined by qRT-PCR based on cDNA as a template using SYBR-Green reagent (Takara, Tokyo, Japan) in the StepOne Plus Real-Time PCR system (Applied Biosystems, Foster City, CA, USA). The PCR conditions were as follows: initial denaturation at $95^{\circ} \mathrm{C}$ for $10 \mathrm{~min}$, followed by 40 amplification cycles of denaturation at $95^{\circ} \mathrm{C}$ for $15 \mathrm{sec}$ and annealing at $60^{\circ} \mathrm{C}$ for $60 \mathrm{sec}$. Housekeeping gene glyceraldehyde-3-phosphate dehydrogenase (GAPDH) served as an internal control. Sp1 mRNA expression was calculated by the $2^{-\Delta \Delta \mathrm{Ct}}$ method. The primer sequences used in our study were as follows: Sp1 forward, 5'-AGTTCCAGACCGTTGATGGG-3' and reverse, 5'-GTT TGCACCTGGTATGATCTGT-3'; GAPDH forward, 5'-GGA GTCCACTGGCGTCTTC-3' and reverse, 5'-GCTGATGAT CTTGAGGCTGTTG-3'. Relative expression of Sp1 mRNA was normalized to GAPDH expression. All reactions were performed in triplicate.

Western blotting. CNE-2 cells were incubated with different concentrations of berberine $(0,25,50,75$ and $100 \mu \mathrm{mol} / \mathrm{l})$ for $24 \mathrm{~h}$, and then the cells were harvested and washed with ice-cold PBS three times. Cell lysates were lysed with RIPA buffer (150 mM NaCl, 1\% NP-40, 0.5\% sodium deoxycholate, $0.1 \%$ SDS $50 \mathrm{mM}$ Tris-Cl, $\mathrm{pH} 7.4)$ containing $20 \%(\mathrm{v} / \mathrm{v})$ protease inhibitor cocktail (Sigma-Aldrich). Then cell lysates were sonicated and incubated on ice for $30 \mathrm{~min}$, followed by centrifugation at $12,000 \mathrm{x} \mathrm{g}$ for $30 \mathrm{~min}$ at $4^{\circ} \mathrm{C}$ for removal of insoluble debris. Protein concentrations were determined by bicinchoninic acid (BCA) protein concentration assay kit (Beijing Biosea Biotechnology Co., Ltd., Beijing, China). Proteins $(50 \mu \mathrm{g})$ were separated on sodium dodecyl 
A

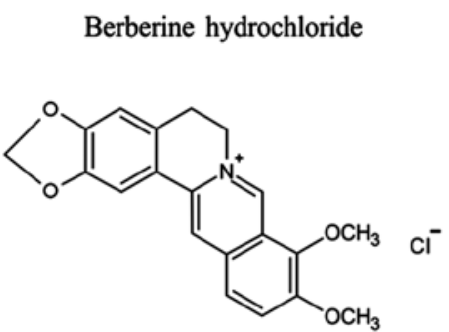

B

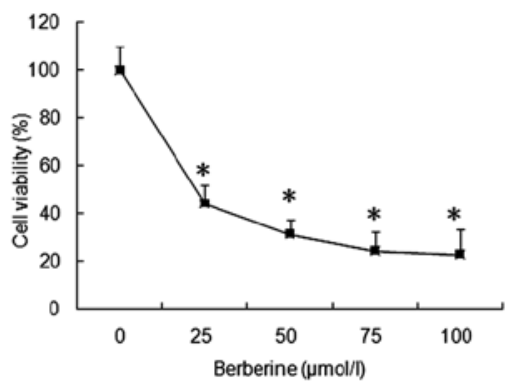

C

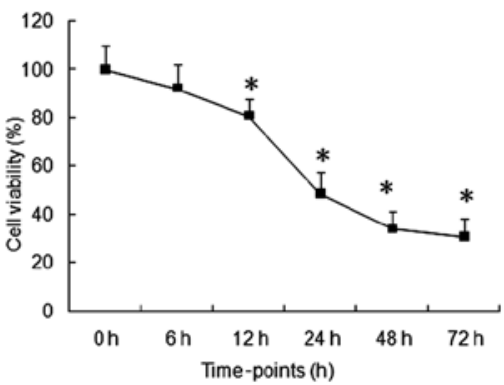

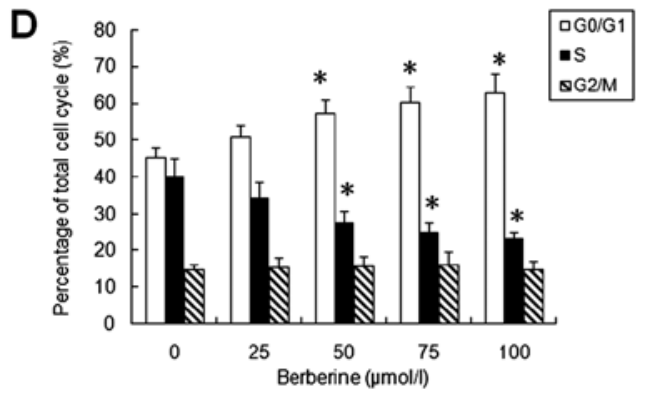
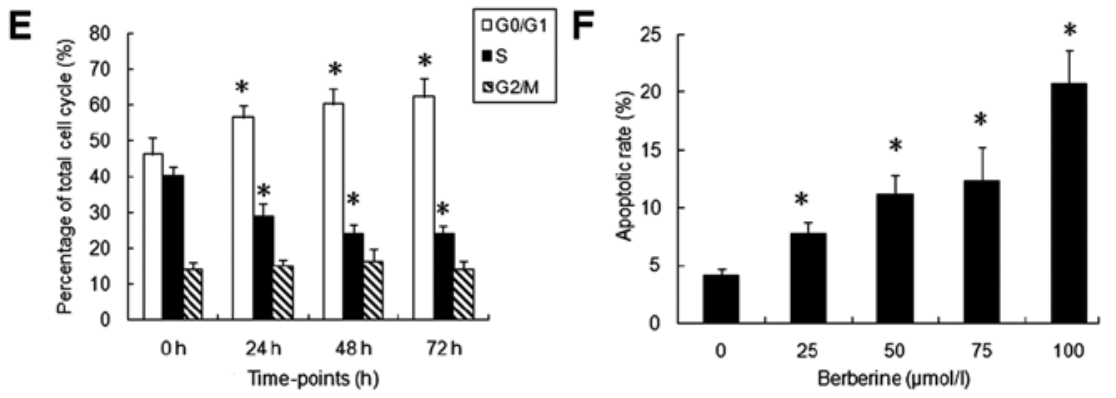

Figure 1. Berberine inhibits cell proliferation, induces cell cycle arrest and apoptosis of nasopharyngeal carcinoma (NPC) cells. (A) Chemical structure of berberine hydrochloride. (B) Berberine inhibits the viability of NPC cells in a concentration-dependent manner. CNE-2 cells were treated with berberine at the indicated concentrations $(0,25,50,75$ and $100 \mu \mathrm{mol} / 1)$ for $72 \mathrm{~h}$, and the cell viability was then determined by MTT assay. (C) Berberine inhibits the viability of NPC cells in a time-dependent manner. CNE-2 cells were treated with $100 \mu \mathrm{mol} / 1$ berberine for $6,12,24,48$ or $72 \mathrm{~h}$. All data are expressed as the mean \pm SD values from three independent experiments and were compared using a two-tailed, unpaired t-test. Cell viability was normalized to that of the untreated control cells. (D) Berberine induced cell cycle arrest at the G0/G1 phase in NPC cells in a concentration-dependent manner. CNE-2 cells were treated with berberine at various concentrations $(0,25,50,75$ and $100 \mu \mathrm{mol} / 1)$ for $72 \mathrm{~h}$, and then were stained with propidium iodide (PI; $20 \mu \mathrm{g} / \mathrm{ml})$ to determine the percentages of cells in the G0/G1, S and G2/M phases. (E) Berberine induced cell cycle arrest in the G0/G1 phase of NPC cells in a time-dependent manner. CNE-2 cells were treated with $100 \mu \mathrm{mol} / 1$ berberine for 24,48 or $72 \mathrm{~h}$, followed by PI staining. (F) Berberine induced cell apoptosis in NPC cells. CNE- 2 cells were treated with various concentrations of berberine $(0,25,50,75$ and $100 \mu \mathrm{mol} / \mathrm{l})$ for $24 \mathrm{~h}$. Significant difference from the control group (berberine concentration is 0 ; or berberine treatment time is 0 ) is denoted by ${ }^{*} \mathrm{P}<0.05$.

sulfate-polyacrylamide gel electrophoresis (SDS-PAGE) gels (polyacrylamide concentration $120 \mathrm{~g} / \mathrm{l}$ ), and then electrophoretically transferred to PVDF membranes (Bio-Rad Laboratories, Inc., Hercules, CA, USA). The membranes were blocked with $3 \%$ BSA in TBS-T buffer $(3 \mathrm{~g} / 1$ Tris base, $8 \mathrm{~g} / 1$ $\mathrm{NaCl}, 0.2 \mathrm{~g} / 1 \mathrm{KCl}, 0.1 \%$ Tween-20, $\mathrm{pH} 7.4)$ at $4^{\circ} \mathrm{C}$. After that, the membranes were incubated with specific mouse monoclonal antibodies against human Sp1, E-cadherin or vimentin (Santa Cruz Biotechnology Inc., Santa Cruz, CA, USA) (all 1:1,000 dilutions), and then incubated with the horseradish peroxidaseconjugated rabbit anti-mouse secondary antibodies (IgG) (1:1,000 dilution) in TBS-T plus 3\% BSA at room temperature for $1 \mathrm{~h}$. The density of the targeted bands in the membranes was visualized using enhanced chemical luminescence (ECL; Pierce ${ }^{\circledR}$ ECL Plus Western Blotting Substrate; Pierce Biotechnology, Inc., Rockford, IL, USA), and the protein bands were detected by Bio-Rad ChemiDoc XRS (Bio-Rad Laboratories, Inc.).

Cell invasion assay. The in vitro invasion capability of the NCE-2 cells was measure by the Boyden chamber invasion assay. In this experiment, 24-well tissue culture plates were used with a Transwell filter membrane. The lower side of the filters was coated with type I collagen $(0.5 \mathrm{mg} / \mathrm{ml})$. Cells $\left(5 \times 10^{4}\right)$ were seeded on the upper side of the filter membrane in $100 \mu$ l DMEM. Cells were incubated with TGF- $\beta 1(5 \mathrm{ng} / \mathrm{ml})$, TGF- $\beta 1+$ BBR $(50 \mu \mathrm{mol} / \mathrm{l})$, or TGF- $\beta 1+$ Mith $(100 \mathrm{nmol} / \mathrm{l})$. Cells treated with DMEM served as the control. After $48 \mathrm{~h}$, cells on the upper surface of the filter were wiped off, and migrated cells on the lower part of filter membrane were stained with crystal violet (Sigma-Aldrich), and counted using light microscopy (x100 magnification) as the numbers of migrated cells. The migrated cells of each group were normalized to those of the untreated controls. Each sample was performed in three independent experiments.

Statistical analysis. All quantitative data are expressed as the mean \pm standard deviation (SD) and were acquired from experiments that were repeated more than three times. Statistical analysis was performed using commercially available software (SPSS version 19.0) (SPSS, Inc., Chicago, IL, USA). A two-tailed unpaired Student's t-test or one-way analysis of variance (ANOVA) was performed to measure the differences between the means of the different groups. $\mathrm{P}<0.05$ was considered to indicate a statistically significant difference.

\section{Results}

Berberine inhibits the proliferation and induces cell cycle arrest and apoptosis in NPC cells. To evaluate the effects of berberine on the cell proliferation of NPC cells, an MTT assay was performed in CNE-2 cells treated with different concentrations of berberine $(25,50,75$ and $100 \mu \mathrm{mol} / \mathrm{l})$ for $72 \mathrm{~h}$, or in CNE- 2 cells treated with $50 \mu \mathrm{mol} / \mathrm{l}$ berberine for $6,12,24,48$ or $72 \mathrm{~h}$. Increasing concentrations of berberine and prolonged time from 12 to $72 \mathrm{~h}$ resulted in significantly 

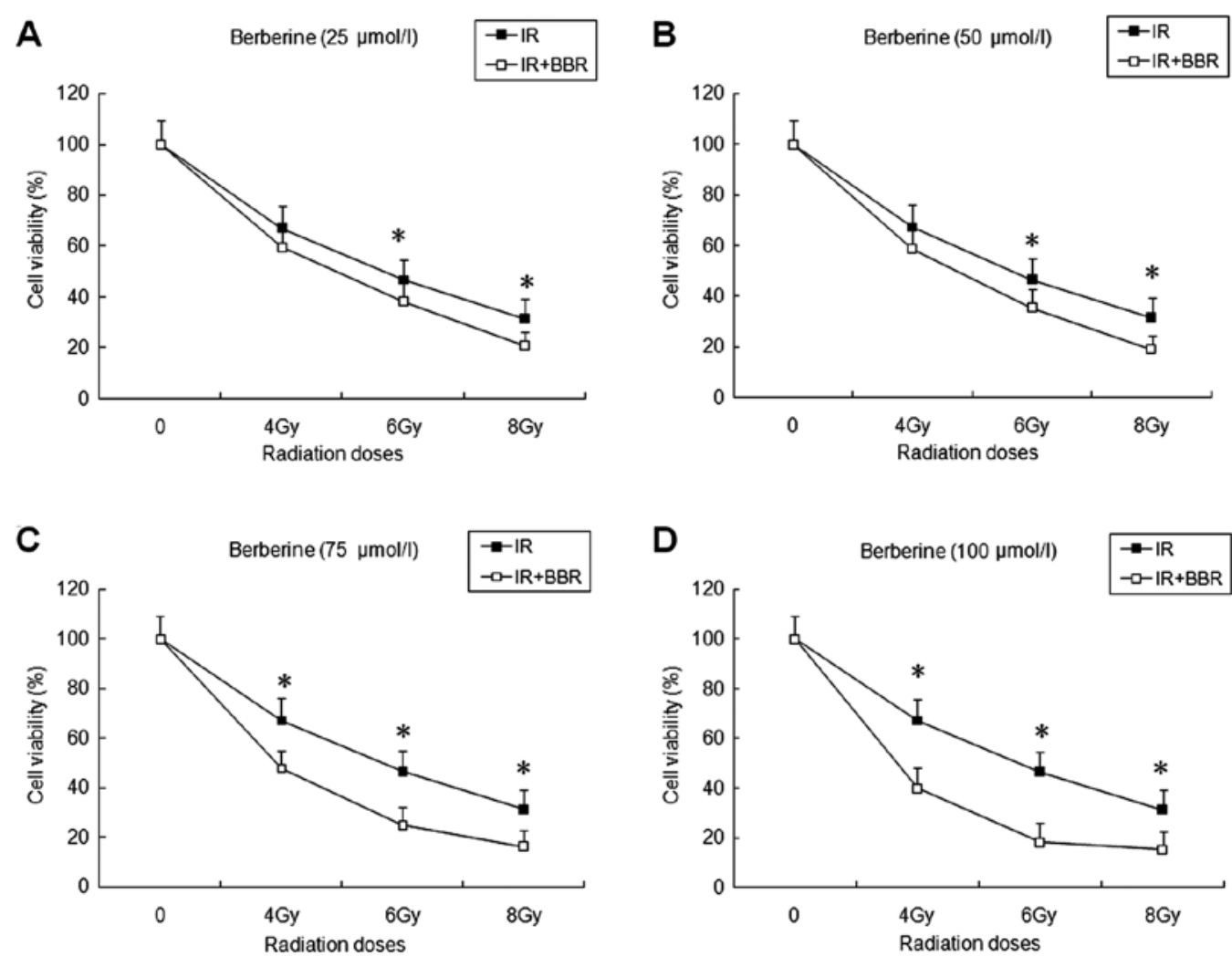

Figure 2. Effects of berberine pretreatment followed by irradiation on the viability of nasopharyngeal carcinoma (NPC) cells. CNE-2 cells were treated with irradiation (4, 6 and $8 \mathrm{~Gy})$ alone or irradiation with a 3-h pretreatment of berberine. After irradiation for $72 \mathrm{~h}$, MTT assay was performed to measure cell viability. Berberine at concentrations of (A) 25 , (B) 50 , (C) 75 and (D) $100 \mu \mathrm{mol} / 1$ all markedly enhanced the radiosensitivity of the CNE-2 cells. All data are expressed as mean \pm SD values from three independent experiments. Significant difference from the irradiation alone group is denoted by ${ }^{*} \mathrm{P}<0.05$.

reduced cell viability in the CNE-2 cells (Fig. 1B and C). This indicates that berberine inhibited NPC cell proliferation in a concentration- and time-dependent manner.

To investigate whether the berberine-induced decrease in CNE-2 cell viability was associated with cell cycle regulation, we analyzed the cell cycle of CNE-2 cells by PI staining in flow cytometry. CNE-2 cells were treated with various concentrations of berberine $(0,25,50,75$ and $100 \mu \mathrm{mol} / \mathrm{l})$ for $72 \mathrm{~h}$, or treated with $50 \mu \mathrm{mol} / 1$ berberine for 24,48 or $72 \mathrm{~h}$. Berberine significantly increased the percentage of cells in the G0/G1 phase at concentrations of 50,75 and $100 \mu \mathrm{mol} / 1$ for $72 \mathrm{~h}$, and at $50 \mu \mathrm{mol} / 1$ for 24,48 and $72 \mathrm{~h}(\mathrm{P}<0.05)$ (Fig. 1D and E). However, the percentage of cells in the G2/M phase remained unchanged after berberine treatment.

We further measured cell apoptosis in CNE-2 cells to explore whether reduced cell viability was caused by cell death. CNE-2 cells were treated with various concentrations of berberine $(0,25,50,75$ and $100 \mu \mathrm{mol} / \mathrm{l})$ for $24 \mathrm{~h}$. Berberine induced cell apoptosis of the CNE-2 cells in a concentration-dependent manner $(\mathrm{P}<0.05)$ (Fig. 1F).

Berberine sensitizes NPC cells to radiation. To evaluate the effects of berberine on the radiosensitivity of NPC cells, an MTT assay was performed. CNE-2 cells were treated with irradiation $(4,6$ and $8 \mathrm{~Gy})$ alone or irradiation with berberine $(25$, 50,75 and $100 \mu \mathrm{mol} / \mathrm{l}$ ) pretreatment for $3 \mathrm{~h}$. After irradiation for $72 \mathrm{~h}$, cell viability was measured. Berberine significantly reduced the proliferation and cell viability of the NPC cells following various doses of irradiation $(\mathrm{P}<0.05)$ (Fig. 2A-D). This indicates that berberine markedly enhanced the radiosensitivity of CNE-2 cells.

Sp1 is a direct target of berberine and is involved in NPC-cell radioresistance. To investigate the molecular mechanism underlying enhanced radiosensitivity of NPC cells by berberine, we performed qRT-PCR and western blotting to measure the Sp1 mRNA and protein expression in CNE-2 cells following incubation with berberine. qRT-PCR showed that berberine decreased Sp1 mRNA in a time-dependent manner $(\mathrm{P}<0.05)($ Fig. 3A). However, treatment with berberine at two concentrations (50 and $100 \mu \mathrm{mol} / \mathrm{l})$ showed similar Sp1 mRNA levels in the NPC cells at a 12-, 24- and 48-h incubation. Western blotting showed that berberine decreased Sp1 protein in a concentration-dependent manner after a $24-\mathrm{h}$ incubation $(\mathrm{P}<0.05)$ (Fig. 3B).

To investigate whether decreased $\mathrm{Sp} 1$ expression participates in the enhanced radiosensitivity of CNE-2 cells by berberine, we analyzed the effect of mithramycin $\mathrm{A}$, a Sp1 specific inhibitor, on the radiosensitivity and apoptosis of NPC cells. CNE-2 cells were treated with irradiation (4, 6 and $8 \mathrm{~Gy})$ alone or irradiation with a 3-h pretreatment of mithramycin A $(100 \mathrm{nmol} / \mathrm{l})$. Mithramycin A significantly reduced the cell viability of the NPC cells following various doses of irradiation $(\mathrm{P}<0.05)$ (Fig. 3C). Furthermore, mithramycin A increased the apoptotic rate in the CNE-2 cells treated with irradiation at $4 \mathrm{~Gy}(\mathrm{P}<0.05)($ Fig. 3D). This indicates that $\mathrm{Sp} 1$ is a molecule 

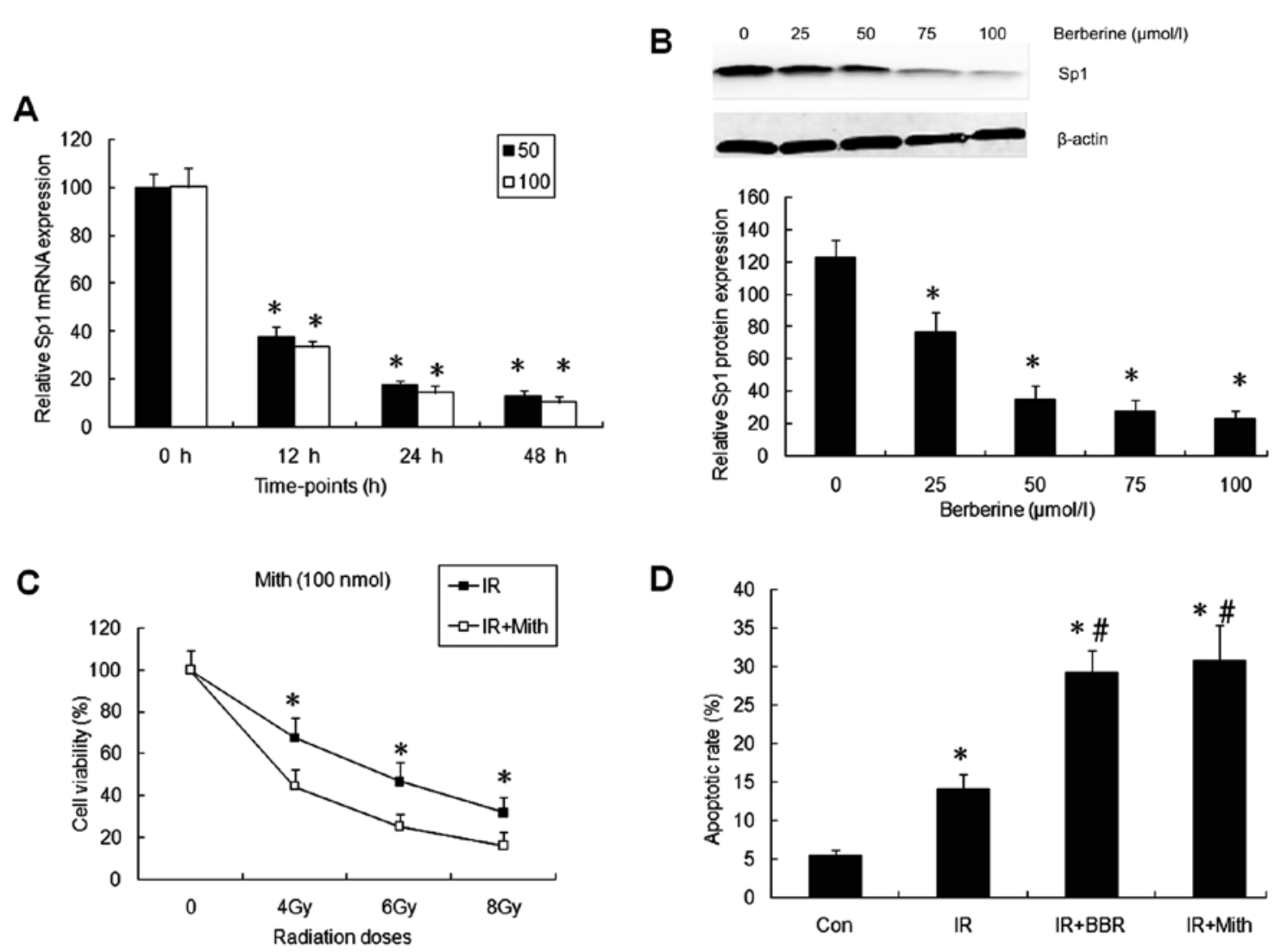

Figure 3. Decreased specificity protein 1 (Sp1) expression is involved in the enhanced radiosensitivity of berberine in nasopharyngeal carcinoma (NPC) cells. (A) qRT-PCR showed that berberine decreased the Sp1 mRNA level in the NPC cells. CNE- 2 cells were treated with various concentrations of berberine (0, 100 and $300 \mu \mathrm{mol} / \mathrm{l}$ ) for 12,24 or $48 \mathrm{~h}$. (B) Western blotting showed that berberine decreased the Sp1 protein level in the NPC cells. Berberine (100 $\mu \mathrm{mol} / \mathrm{l})$ was incubated with CNE-2 cells for $24 \mathrm{~h}$. Significant difference from the control group (berberine treatment time is 0 ; or berberine concentrations is 0 ) is denoted by ${ }^{*} \mathrm{P}<0.05$. (C) Mithramycin A (Mith) enhanced the radiosensitivity of CNE-2 cells. CNE-2 cells were treated with irradiation (4, 6 and 8 Gy) alone or irradiation with Mith $(100 \mathrm{nmol} / \mathrm{l})$ pretreatment for $3 \mathrm{~h}$, and then grown for 3 days. Significant difference from the irradiation alone group is denoted by ${ }^{*} \mathrm{P}<0.05$. (D) Mith increased the apoptotic rate in CNE-2 cells treated with irradiation. CNE-2 cells were treated with irradiation (4 Gy) alone, irradiation with berberine (BBR; $100 \mu \mathrm{mol} / \mathrm{l})$ pretreatment, or irradiation with Mith (100 nmol/l) pretreatment for $3 \mathrm{~h}$. Significant difference from the control group is denoted by ${ }^{*} \mathrm{P}<0.05$. Significant difference from the irradiation alone group is denoted by ${ }^{*} \mathrm{P}<0.05$.

essential for the radioresistance of NPC cells and decreased Sp1 expression may be involved in the radiosensitivity induced by berberine.

Berberine suppresses tumor invasion and EMT by decreasing Spl expression in NPC cells. In order to explore the detailed pathway regulated by $\mathrm{Sp} 1$ in the berberine-induced enhanced radiosensitivity of NPC cells, we aimed to confirm whether berberine affects the tumor invasion induced by TGF- $\beta 1$. CNE- 2 cells were treated with DMEM (control group), TGF- $\beta 1$ $(5 \mathrm{ng} / \mathrm{ml})$ (TGF- $\beta$ group), TGF- $\beta 1+$ berberine $(50 \mu \mathrm{mol} / \mathrm{l})$ (BBR group), or TGF- $\beta 1+$ mithramycin A (100 nmol/l) (Mith group), and a Boyden chamber assay was used to determine the impact of berberine on CNE-2 cell invasion. Tumor invasion was significantly increased in the TGF- $\beta 1$ group than that noted in the control group $(\mathrm{P}<0.05)$ (Fig. 4A). This result showed that TGF- $\beta 1$ promoted NPC cell metastasis. Berberine and mithramycin A both inhibited CNE-2 cell invasion induced by TGF- $\beta 1$, and the differences between the TGF- $\beta 1$ group and the BBR group or Mith group were significant $(\mathrm{P}<0.05)$.

We further explored whether berberine could inhibit TGF- $\beta 1$-induced EMT. CNE-2 cells showed a mesenchymal phenotype after treatment with TGF- $\beta 1(5 \mathrm{ng} / \mathrm{ml})$ for $48 \mathrm{~h}$. However, after adding berberine $(50 \mu \mathrm{mol} / \mathrm{l})$ or mithramycin A
$(100 \mathrm{nmol} / \mathrm{l})$, the cells changed from a mesenchymal back to an epithelial morphology (Fig. 4B). To confirm the inhibitory effect of berberine on EMT, we performed western blotting to determine the protein expression of two EMT markers, E-cadherin and vimentin. Compared with the control group, TGF- $\beta 1$ decreased the expression of epithelial phenotype marker E-cadherin and increased the expression of mesenchymal phenotype marker vimentin $(\mathrm{P}<0.05)$ (Fig. $4 \mathrm{C}$ and $\mathrm{D}$ ). After treatment with berberine or mithramycin A, the E-cadherin protein was increased and vimentin protein was decreased significantly $(\mathrm{P}<0.05)$. These findings indicate that berberine inhibited the EMT process by TGF- $\beta 1$ through increased E-cadherin and decreased vimentin expression in the NPC cells, and its mechanism may be associated with decreased Sp1 expression.

\section{Discussion}

In the present study, we showed that berberine inhibited proliferation and induced cell cycle arrest in the G0/G1 phase and apoptosis in CNE-2 cells. Berberine enhanced the radiosensitivity of CNE-2 cells and this was associated with the downregulation of Sp1 mRNA and protein expression. Furthermore, berberine suppressed tumor invasion and 
A

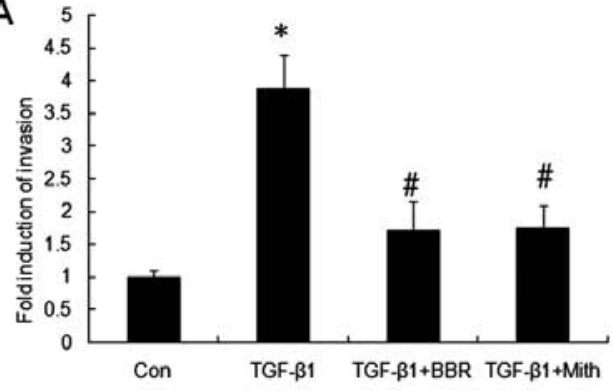

C

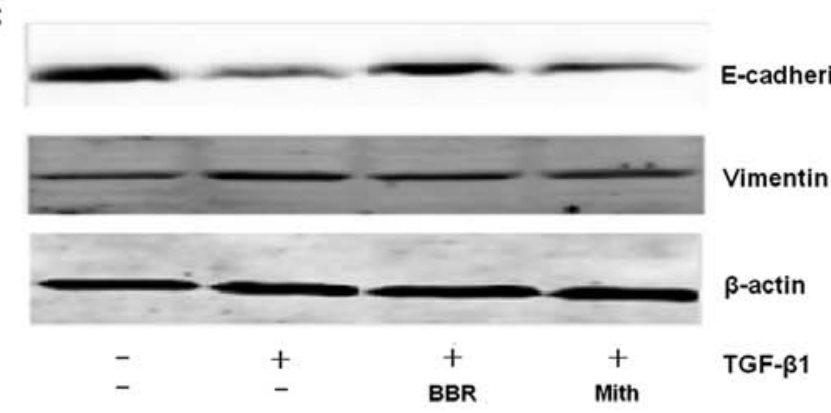

B

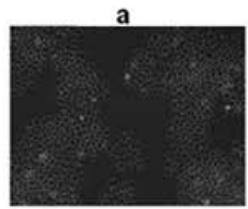

$-$

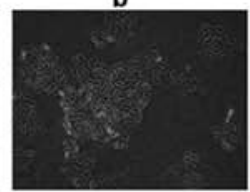

$+$ c

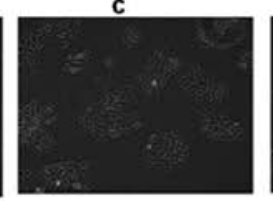

$+$

BBR

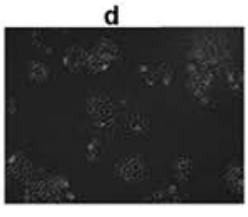

$+$

TGF- $\beta 1$

D
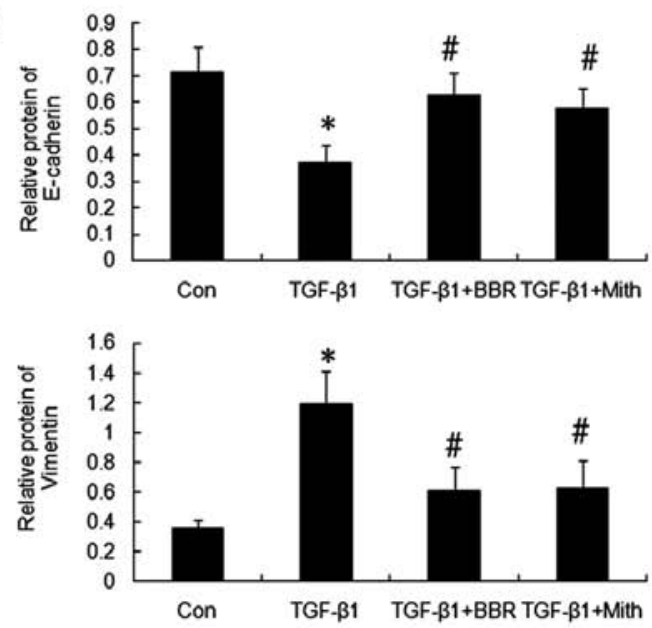

Figure 4. Berberine suppresses tumor invasion and EMT process by decreasing Sp1 expression in NPC cells. CNE- 2 cells were treated with TGF- $\beta 1$ ( $5 \mathrm{ng} / \mathrm{ml})$, TGF- $\beta 1+B B R(50 \mu \mathrm{mol} / 1)$, or TGF- $\beta 1+$ Mith (100 nmol/l). Cells treated with DMEM served as the control. (A) Berberine inhibited tumor invasion of NPC cells induced by TGF- $\beta 1$. The invasive capability of CNE- 2 cells was measured by Boyden chamber assay. Cells were seeded on the upper side of well plates followed by serum starvation. After 48 -h incubation of TGF- $\beta 1$, BBR or Mith, cells that had migrated to the lower side of the well plates were counted, and values were normalized to the untreated controls. Cell invasion was enhanced by TGF- $\beta 1$ treatment, and was attenuated by BBR or Mith treatment. (B) Berberine inhibited EMT morphology of the NPC cells induced by TGF- $\beta 1$ at $48 \mathrm{~h}$. Control CNE2 cells displayed classical epithelial morphology, and TGF- $\beta 1$-treated cells showed a mesenchymal-like phenotype. Berberine and Mith inhibited the EMT process induced by TGF- $\beta 1$. (C) Protein levels of E-cadherin and vimentin were measured by western blot assay in the CNE-2 cells. One representative figure is shown from three independent experiments. (D) Effects of berberine on EMT marker genes in the TGF- $\beta 1$-treated CNE-2 cells. The density of the protein bands were converted into grayscale values and normalized to that of the internal control $\beta$-actin. Results are expressed as mean $\pm \mathrm{SD}$. Western blot analysis was performed $24 \mathrm{~h}$ after treatment. $\beta$-actin served as the loading control. Significant difference from the control group is denoted by ${ }^{~} \mathrm{P}<0.05$. Significant difference from the TGF- $\beta 1$ group is denoted by ${ }^{*} \mathrm{P}<0.05$.

EMT of CNE-2cells induced by TGF- $\beta 1$, as evidenced by increased expression of epithelial marker E-cadherin and decreased expression of mesenchymal marker vimentin. Selective inhibition of Sp1 by mithramycin A enhanced radiosensitivity and inhibited tumor invasion and EMT of CNE- 2 cells induced by TGF- $\beta 1$. Therefore, Sp1 participates in the enhanced radiosensitivity induced by berberine and is required for TGF- $\beta 1$-induced invasion and EMT of NPC cells.

Radioresistance is the primary cause of poor prognosis of advanced-stage NPC. Therefore, biomarkers with radiosensitizing effects have been widely explored to improve the clinical outcome of NPC (14). We found that berberine enhanced the radiosensitivity of NPC cells, which may be associated with reduced proliferation, cell cycle arrest and apoptosis of NPC cells. The results of our study are consistent with other studies showing the radiosensitizing effects of berberine in NPC, which was associated with decreased expression of hypoxia-inducible factor-1 $\alpha$ (12). In fact, berberine was found to enhance the radiosensitivity of a variety of cancers, including esophageal, breast, esophageal squamous and prostate cancers (15-18). This indicates that the radiosensitizing effects of berberine are universal in many types of cancers, and its mechanism in cancers including NPC warrants extensive investigation.
In the present study, we firstly found that berberine can downregulate $\mathrm{Sp} 1$ expression in NPC cells, which is involved in the radiosensitizing effects of berberine. $\mathrm{Sp} 1$ is one transcription factor and can bind GC/GT-rich promoter elements and regulate the promoter activity of multiple genes involved in cell cycle, differentiation and oncogenesis (19). In NPC cells, Spl cooperates with c-MYC to bind the promoter of the BMI1 gene and participates in the pathogenesis of NPC (20). In fact, Sp1 was overexpressed in advanced NPC tissues and downregulation of Sp1 inhibited cell proliferation and clonogenicity of NPC cells (21). Sp1 DNA binding was increased within $30 \mathrm{~min}$ after ionizing radiation in radioresistant human malignant melanoma (U1-Mel) cells (22), which indicates that Sp1 may participate in the induction of genes in radioresistance. However, currently there are few studies concerning the association between Sp1 and the radioresistance of cancers. Our previous study found a correlation between high expression of $\mathrm{Sp} 1$ and radioresistance of NPC (13). Furthermore, this study confirmed Sp1 as a therapeutic target of the radiosensitizing effects on NPC induced by berberine.

EMT is a cellular process characterized by decreased cell-cell adhesion and increased cell motility, and is involved in cancer progression, metastasis and increased resistance to radiotherapy (23). EMT not only decreases the radiosensitivity 
of cancers but also can be induced by radiation itself. Therefore, inhibition of EMT is an effective therapeutic strategy for enhancing the radiosensitivity of cancers (24). Berberine has been reported to suppress EMT in lung cancer, cervical cancer, prostate cancer and NPC (25-28). However, whether inhibition of EMT is involved in the radiosensitizing effects of berberine remains unclear. This study found that berberine inhibited TGF- $\beta 1$-induced EMT in NPC cells, and increased epithelial marker E-cadherin and decreased mesenchymal marker vimentin. It has been reported that E-cadherin loss in EMT promotes radioresistance in human tumor cells (29). Therefore, in our study increased E-cadherin and decreased EMT may also have induced the radiosensitizing effects of berberine. In addition, EMT is an inducer of tumor invasion. In the present study, berberine inhibited CNE- 2 cell invasion induced by TGF- $\beta 1$, and suppression of EMT may be an important cause of this decreased invasion. This indicates that in NPC cells, berberine inhibits the EMT process, and subsequently enhances radiosensitivity and decreases invasion.

To further explore the detailed mechanism through which berberine suppresses EMT, we treated NPC cells with mithramycin $A$, a selective Sp1 inhibitor. We found that inhibition of $\mathrm{Sp} 1$ enhanced radiosensitivity and suppressed invasion and EMT, which was similar to the effects of berberine. This indicates that $\mathrm{Spl}$ lies in the upstream of EMT and radioresistance in NPC cells. The relationship between Sp1 and EMT is unclear. It was reported that $\mathrm{Sp} 1$ is essential to maintain an epithelial state and inhibits the EMT process (30). However, other studies demonstrated a significant inhibitory effect on EMT by the silencing Sp1 (31). Sp1 can also cooperate with ZEB2 to activate mesenchymal genes and promote EMT (32). The controversial effect of Sp1 on EMT may be caused by the fact that $\mathrm{Sp} 1$ is a transcription factor and can activate or repress various genes. In fact, $\mathrm{Sp} 1$ mainly acts as a promoter of EMT. High expression of Sp1 has been reported to enhance invasion and migration in lung, breast, ovarian and pancreatic cancer (33-36). Therefore, targeting and silencing of Spl can inhibit the invasion and migration of cancers $(37,38)$. Our study presents berberine as a novel agent by inhibition of Sp1, and suppressed EMT and invasion and enhanced radiosensitivity of NPC. We also hypothesize a signaling pathway Sp1-EMTradioresistance in epithelial cancers, at least in NPC.

In conclusion, the present study confirmed berberine as a radiosensitizing agent for NPC, and the underlying mechanism is associated with inhibition of Sp1, EMT and invasion. Our study demonstrated the regulation of Sp1 by berberine and suggests that Sp1 may be one important promoter of radioresistance in epithelial cancers. Our study provides new insights into the regulation of Sp1 and EMT in radioresistance and cancer migration and progression. Further study is needed to explore the detailed mechanisms through which Sp1 promotes EMT and radioresistance in NPC and other epithelial cancers.

\section{References}

1. Wei WI and Sham JS: Nasopharyngeal carcinoma. Lancet 365 2041-2054, 2005.

2. Lo KW, Chung GT and To KF: Deciphering the molecular genetic basis of NPC through molecular, cytogenetic, and epigenetic approaches. Semin Cancer Biol 22: 79-86, 2012.
3. Lee AW: Contribution of radiotherapy to function preservation and cancer outcome in primary treatment of nasopharyngeal carcinoma. World J Surg 27: 838-843, 2003.

4. Chen WC, McBride WH, Chen SM, Lee KF, Hwang TZ, Jung SM, Shau H, Liao SK, Hong JH and Chen MF: Prediction of poor survival by cyclooxygenase- 2 in patients with T4 nasopharyngeal cancer treated by radiation therapy: clinical and in vitro studies. Head Neck 27: 503-512, 2005.

5. Loomans HA and Andl CD: Intertwining of activin A and TGF $\beta$ signaling: dual roles in cancer progression and cancer cell invasion. Cancers (Basel) 7: 70-91, 2014.

6. Roberts $\mathrm{AB}$ and Wakefield LM: The two faces of transforming growth factor beta in carcinogenesis. Proc Natl Acad Sci USA 100: 8621-8623, 2003.

7. Katsuno Y, Lamouille S and Derynck R: TGF- $\beta$ signaling and epithelial-mesenchymal transition in cancer progression. Curr Opin Oncol 25: 76-84, 2013.

8. Zhang P, Liu H, Xia F, Zhang QW, Zhang YY, Zhao Q, Chao ZH, Jiang ZW and Jiang CC: Epithelial-mesenchymal transition is necessary for acquired resistance to cisplatin and increases the metastatic potential of nasopharyngeal carcinoma cells. Int J Mol Med 33: 151-159, 2014.

9. Kumar A, Ekavali, Chopra K, Mukherjee M, Pottabathini R and Dhull DK: Current knowledge and pharmacological profile of berberine: an update. Eur J Pharmacol 761: 288-297, 2015.

10. Tang F, Wang D, Duan C, Huang D, Wu Y, Chen Y, Wang W, Xie C, Meng J, Wang L, et al: Berberine inhibits metastasis of nasopharyngeal carcinoma $5-8 \mathrm{~F}$ cells by targeting Rho kinase-mediated Ezrin phosphorylation at threonine 567. J Biol Chem 284: 27456-27466, 2009.

11. Tsang CM, Cheung YC, Lui VW, Yip YL, Zhang G, Lin VW, Cheung KC, Feng Y and Tsao SW: Berberine suppresses tumorigenicity and growth of nasopharyngeal carcinoma cells by inhibiting STAT3 activation induced by tumor associated fibroblasts. BMC Cancer 13: 619, 2013.

12. Zhang C, Yang X, Zhang Q, Yang B, Xu L, Qin Q, Zhu H, Liu J, Cai J, Tao G, et al: Berberine radiosensitizes human nasopharyngeal carcinoma by suppressing hypoxia-inducible factor- $1 \alpha$ expression. Acta Otolaryngol 134: 185-192, 2014.

13. Wang J, Kang M, Qin YT, Wei ZX, Xiao JJ and Wang RS: Sp1 is over-expressed in nasopharyngeal cancer and is a poor prognostic indicator for patients receiving radiotherapy. Int J Clin Exp Pathol 8: 6936-6943, 2015.

14. Chen W and Hu GH: Biomarkers for enhancing the radiosensitivity of nasopharyngeal carcinoma. Cancer Biol Med 12: 23-32, 2015.

15. Liu Q, Jiang H, Liu Z, Wang Y, Zhao M, Hao C, Feng S, Guo H, $\mathrm{Xu} \mathrm{B}$, Yang Q, et al: Berberine radiosensitizes human esophageal cancer cells by downregulating homologous recombination repair protein RAD51. PLoS One 6: e23427, 2011.

16. Wang J,Liu Q and Yang Q: Radiosensitization effects of berberine on human breast cancer cells. Int J Mol Med 30: 1166-1172, 2012.

17. Yang X, Yang B, Cai J, Zhang C, Zhang Q, Xu L, Qin Q, Zhu H, Ma J, Tao G, et al: Berberine enhances radiosensitivity of esophageal squamous cancer by targeting HIF-1 $\alpha$ in vitro and in vivo. Cancer Biol Ther 14: 1068-1073, 2013.

18. Zhang Q, Zhang C, Yang X, Yang B, Wang J, Kang Y, Wang Z, Li D, Huang G, Ma Z, et al: Berberine inhibits the expression of hypoxia induction factor-1alpha and increases the radiosensitivity of prostate cancer. Diagn Pathol 9: 98, 2014.

19. Davie JR, He S, Li L, Sekhavat A, Espino P, Drobic B, Dunn KL, Sun JM, Chen HY, Yu J, et al: Nuclear organization and chromatin dynamics - Sp1, Sp3 and histone deacetylases. Adv Enzyme Regul 48: 189-208, 2008.

20. Wang HB, Liu GH, Zhang H, Xing S, Hu LJ, Zhao WF, Xie B, Li MZ, Zeng BH, Li Y, et al: Sp1 and c-Myc regulate transcription of BMI1 in nasopharyngeal carcinoma. FEBS J 280: 2929-2944, 2013.

21. Zhang JP, Zhang H, Wang HB, Li YX, Liu GH, Xing S, Li MZ and Zeng MS: Down-regulation of Spl suppresses cell proliferation, clonogenicity and the expressions of stem cell markers in nasopharyngeal carcinoma. J Transl Med 12: 222, 2014.

22. Yang CR, Wilson-Van Patten C, Planchon SM, WuerzbergerDavis SM, Davis TW, Cuthill S, Miyamoto S and Boothman DA: Coordinate modulation of Sp1, NF-kappa B, and p53 in confluent human malignant melanoma cells after ionizing radiation. FASEB J 14: 379-390, 2000.

23. Marie-Egyptienne DT, Lohse I and Hill RP: Cancer stem cells, the epithelial to mesenchymal transition (EMT) and radioresistance: potential role of hypoxia. Cancer Lett 341: 63-72, 2013. 
24. Zhang X, Zheng L, Sun Y, Wang T and Wang B: Tangeretin enhances radiosensitivity and inhibits the radiation-induced epithelial-mesenchymal transition of gastric cancer cells. Oncol Rep 34: 302-310, 2015.

25. Qi HW, Xin LY, Xu X, Ji XX and Fan LH: Epithelial-to-mesenchymal transition markers to predict response of Berberine in suppressing lung cancer invasion and metastasis. J Transl Med 12: 22, 2014

26. Chu SC, Yu CC, Hsu LS, Chen KS, Su MY and Chen PN Berberine reverses epithelial-to-mesenchymal transition and inhibits metastasis and tumor-induced angiogenesis in human cervical cancer cells. Mol Pharmacol 86: 609-623, 2014.

27. Liu CH, Tang WC, Sia P, Huang CC, Yang PM, Wu MH, Lai IL and Lee KH: Berberine inhibits the metastatic ability of prostate cancer cells by suppressing epithelial-to-mesenchymal transition (EMT)-associated genes with predictive and prognostic relevance. Int J Med Sci 12: 63-71, 2015.

28. Li CH, Wu DF, Ding H, Zhao Y, Zhou KY and Xu DF: Berberine hydrochloride impact on physiological processes and modulation of twist levels in nasopharyngeal carcinoma CNE-1 cells. Asian Pac J Cancer Prev 15: 1851-1857, 2014.

29. Theys J, Jutten B, Habets R, Paesmans K, Groot AJ, Lambin P, Wouters BG, Lammering G and Vooijs M: E-cadherin loss associated with EMT promotes radioresistance in human tumor cells. Radiother Oncol 99: 392-397, 2011.

30. Kolesnikoff N, Attema JL, Roslan S, Bert AG, Schwarz QP, Gregory PA and Goodall GJ: Specificity protein 1 (Sp1) maintains basal epithelial expression of the miR-200 family: implications for epithelial-mesenchymal transition. J Biol Chem 289: 11194-11205, 2014.

31. Sung WJ, Kim KH, Kim YJ, Chang YC, Lee IH and Park KK: Antifibrotic effect of synthetic Smad/Spl chimeric decoy oligodeoxynucleotide through the regulation of epithelial mesenchymal transition in unilateral ureteral obstruction model of mice. Exp Mol Pathol 95: 136-143, 2013.
32. Nam EH, Lee Y, Park YK, Lee JW and Kim S: ZEB2 upregulates integrin $\alpha 5$ expression through cooperation with Sp1 to induce invasion during epithelial-mesenchymal transition of human cancer cells. Carcinogenesis 33: 563-571, 2012.

33. Kim WY, Jang JY, Jeon YK, Chung DH, Kim YG and Kim CW: Syntenin increases the invasiveness of small cell lung cancer cells by activating p38, AKT, focal adhesion kinase and SP1. Exp Mol Med 46: e90, 2014

34. Kong LM, Liao CG, Zhang Y, Xu J, Li Y, Huang W, Zhang Y, Bian $\mathrm{H}$ and Chen $\mathrm{ZN}$ : A regulatory loop involving miR-22, Sp1, and c-Myc modulates CD147 expression in breast cancer invasion and metastasis. Cancer Res 74: 3764-3778, 2014.

35. Zhao J, Ye W, Wu J, Liu L, Yang L, Gao L, Chen B, Zhang F, Yang H and Li Y: Sp1-CD147 positive feedback loop promotes the invasion ability of ovarian cancer. Oncol Rep 34: 67-76, 2015.

36. Tan Y, Yin H, Zhang H, Fang J, Zheng W, Li D, Li Y, Cao W, Sun C, Liang Y, et al: Sp1-driven up-regulation of miR-19a decreases RHOB and promotes pancreatic cancer. Oncotarget 6 : 17391-17403, 2015.

37. Jiang J, Lv X, Fan L, Huang G, Zhan Y, Wang M and Lu H: MicroRNA-27b suppresses growth and invasion of NSCLC cells by targeting Sp1. Tumour Biol 35: 10019-10023, 2014.

38. Zhang R, Luo H, Wang S, Chen W, Chen Z, Wang HW, Chen Y, Yang J, Zhang X, Wu W, et al: MicroRNA-377 inhibited proliferation and invasion of human glioblastoma cells by directly targeting specificity protein 1. Neuro-oncol 16: 1510-1522, 2014. 